\title{
Effect of roscovitine on nuclear maturation, MPF and MAP kinase activity and embryo development of prepubertal goat oocytes
}

\author{
Ana Raquel Jimenez-Macedo, Dolors Izquierdo, Aixa Urdaneta, \\ Begoña Anguita, Maria-Teresa Paramio* \\ Departament de Ciència Animal i dels Aliments, Facultat de Veterinària, \\ Universitat Autònoma de Barcelona, Bellaterra, Barcelona, Spain
}

Received 1 June 2005; received in revised form 7 October 2005; accepted 13 October 2005

\begin{abstract}
The low number of embryos obtained from IVM-IVF-IVC of prepubertal goat oocytes could be due to an incomplete cytoplasmic maturation. Roscovitine (ROS) inhibits MPF and MAP kinase activity and maintains the oocyte at Germinal Vesicle (GV) stage. The aim of this study was to determine if meiotic activity is arrested in prepubertal goat oocytes cultured with $0,12.5,25,50$ and $100 \mu \mathrm{M}$ of ROS for $24 \mathrm{~h}$. A group of oocytes from adult goats was cultured with $25 \mu \mathrm{M}$ of ROS to compare the effect of ROS on prepubertal and adult goat oocytes. A sample of oocytes was stained to evaluate the nuclear stage at oocyte collection time and after ROS incubation. IVM-oocytes not exposed to ROS formed the control group. Prepubertal goat IVM-oocytes were inseminated and cultured for 8 days. The percentage of oocytes at GV stage, after exposition to ROS was significantly higher in adult goat oocytes $(64.5 \%)$ than in prepubertal goat oocytes. No differences were found among 25, 50 and $100 \mu \mathrm{M}$ ROS concentrations (29, 23 and 26\%, oocytes at GV stage, respectively). After 8 days of culture, no differences in total embryos were observed between control oocytes and oocytes treated with 12.5 and $25 \mu \mathrm{M}(45.2,36.1$ and $39.4 \%$, respectively), however the percentage of blastocysts was higher in the control group. Western blot for the MAPK and p $34^{\mathrm{cdc} 2}$ showed that both enzymes were active in prepubertal goat oocytes after $24 \mathrm{~h}$ of ROS exposition. In conclusion, a low percentage of prepubertal goat oocytes reached GV stage after ROS incubation; possibly because
\end{abstract}

\footnotetext{
* Corresponding author. Tel.: +34 935811456; fax: +34 935811494.
}

E-mail address: teresa.paramio@uab.es (M.-T. Paramio). 
most of them had reinitiated the meiosis inside the follicle. ROS did not affect fertilization or total embryos but ROS showed a negative effect on blastocyst development.

(C) 2005 Published by Elsevier Inc.

Keywords: Goat; IVF; Oocytes; Roscovitine; MPF; MAPK

\section{Introduction}

Goat oocytes, like other mammalian oocytes, are arrested at the diplotene stage of the first meiotic prophase: the so-called germinal vesicle (GV) stage. During oocyte maturation, the meiotical process reaches metaphase II stage (MII) where oocytes will be arrested until fertilization or parthenogenetic activation. In vivo, mammalian oocytes acquire cytoplasmic maturity (capacitation) and the competence to resume meiosis (maturation) during follicle and oocyte growth [1,2]. Thus, both nuclear and cytoplasmic maturation are required to ensure normal fertilization and embryo development. In vitro, when fully grown oocytes are removed from their follicles to the culture medium they can resume meiosis spontaneously despite cytoplasmic maturity.

In oocytes from prepubertal goats, although there is a high percentage $(72 \%)$ of nuclear maturation [3] the number of blastocysts obtained $(<10 \%)$ is low [4]. A high percentage of polyspermic fertilization and failure of male pronucleus formation has been observed in IVM-IVF prepubertal goat oocytes, as has been observed in calf oocytes [5]. This is attributed to an abnormal or incomplete cytoplasmic maturation of these oocytes.

Several authors have hypothezed that if oocytes are cultured in vitro, before maturation, under conditions that maintain oocytes arrested at GV stage, they may have more chance of completing the process of cytoplasm maturation [6-9]. The oocyte growth phase is characterized by an increase in the synthesis and storage of proteins and RNA [10]. Mobilization of these stored products will be used for meiotic and early embryo developmental events. The major changes that occur during oocyte maturation are related to protein phosphorylation. Correlated with this burst of phosphorylation is the activation of two major M-phases kinases: M-phase promoting factor (MPF) [11] and mitogenactivated protein kinase (MAPK). MPF is a member of the cyclin dependent proteinkinases. It is a heterodimer formed by two subunits: $\mathrm{p} 34^{\mathrm{cdc} 2}$ (catalytic subunit) and cyclin B (regulator subunit), which is a homologue of cdc13 in yeast [12]. During oocyte growth, the inactive pre-MPF is phosphorylated at Thr 161 , Thr 14 and Tyr 15 of p34 $4^{\text {cdc2 }}$. This phosphorylation is partly catalyzed by the weel kinase [13]. During oocyte maturation, MPF is activated by specific dephosphorylation of Tyr 15 catalyzed by the cdc25 phosphatase [14]. The other major group of enzymes implicated in oocyte maturation is the MAPK family, also called extracellular signal-regulated kinases (ERKs). MAPK is formed by at least two subunits (p42-ERK2 and p44-ERK1) [15]. In the oocyte, intracellular signals like c-mos orc-ras directly activate MAPK or indirectly activate MEKinases, which would activate MAPK, through phosphorylation, at the onset of oocyte maturation [16]. Independently of the differences between animal species, MPF and MAPK activation are both important in oocyte maturation. Interference in any of these processes will inhibit 
MPF and MAPK activation, preventing resumption of meiosis and arresting the oocyte at GV stage. Different pharmacological meiotic inhibitors have been studied, some of them acting on protein synthesis, such as cyclohexamide [17], and others acting on phosphorylation pathways, such as 6-dimethylaminopurine [17-19]. However, these meiotic inhibitors caused a drastic loss in embryo developmental ability. Other treatments, such as dibutyryl-cAMP (dbcAMP) or 3-isobutyl-1-methyl-xanthine (IBMX) molecules, block bovine oocytes at GV by maintaining a high intracytoplasmic cAMP concentration, but these treatments result only in a transient delay of meiotic resumption. Several authors have used roscovitine as a meiotic inhibitor. Roscovitine is a purine known as a specific inhibitor of cyclin-dependent protein kinases that prevents $\mathrm{p} 34^{\text {cdc2 }}$ dephosphorylation and inhibits MPF kinase activity [20]. Meijer and Kim [20] showed that high concentrations of roscovitine also act on MAPK activity. In fact, Motlik et al. [21] showed that the activation of MAPK by okadaic acid was sufficient to trigger meiotic resumption in porcine oocytes arrested at the GV stage by butyrolactone I (another MPF inhibitor). Roscovitine has been successfully used to arrest meiotic activation without compromising further embryo development in cattle [21,6] and pigs [22]. In horse oocytes [7], ROS did not affect early embryo development of oocytes subjected to ICSI and cultured for $96 \mathrm{~h}$. Ponderato et al. $[8,9]$ used a combination of roscovitine and butyrolactone I to arrest meiotic activation without negative effects on the embryo development of cattle oocytes.

In goat oocytes, Ma et al. [23] observed that hypoxanthine was a concentration-related meiotic inhibitor, but this inhibition declined gradually after $6 \mathrm{~h}$ of culture. Goat oocytes underwent normal nuclear maturation following hypoxanthine inhibition but no results were described for embryo development of these oocytes.

The aim of this study is to improve in vitro embryo development of prepubertal goat oocytes, studying the effectiveness of roscovitine as a prematuration medium on meiotic resumption and activity of MAPK and $\mathrm{p} 34^{\mathrm{cdc2}}$ of these oocytes.

\section{Materials and methods}

\subsection{Oocyte collection}

Oocytes from multiparous, adult goats were recovered from two goats previously treated with sponges of FGA (Intervet, Salamanca, Spain) during 11 days and at day 9 injected with prostagladin F2 $\alpha$ (Estrumate, Pitman-Moore, Madrid, Spain) and $5 \mathrm{~mL}$ of porcine-FSH (Pluset, Calier, Barcelona, Spain) in three doses of 2, 2 and $1 \mathrm{~mL}$ at $12 \mathrm{~h}$ of interval. At day 11, goats were slaughtered and ovaries were immediately transported to the laboratory. Prepubertal goat (30-45 days old) ovaries were obtained from a commercial slaughterhouse and transported to the laboratory within $2 \mathrm{~h}$ of slaughter.

The ovaries were rinsed in solution Dulbecco's phosphate-buffered saline (PBS, P4417, Sigma Chemical Co., St. Louis, MO, USA) with $50 \mu \mathrm{g} / \mathrm{mL}$ of gentamycin sulphate at temperature of $38.5^{\circ} \mathrm{C}$. The cumulus-oocyte complexes (COCs) of adult goats were recovered by follicular aspiration of healthy follicles higher than $3 \mathrm{~mm}$ diameter. Oocytes of prepubertalgoats were recovered by slicing in TCM199 (M-2520, Sigma), supplemented with $2.2 \mathrm{mg} / \mathrm{mL} \mathrm{NaHCO} 3,2 \%$ (v/v) steer serum (Donor Bovine Serum ${ }^{\circledR}$, CanSera, Ont., 
Canada) and $50 \mu \mathrm{g} / \mathrm{mL}$ gentamycin at a temperature of $38.5^{\circ} \mathrm{C}$. Only COCs with at least three intact layers of compact cumulus cells and homogeneous cytoplasm were selected. Selected COCs were washed in TCM199.

\subsection{In vitro prematuration (exposition of oocytes to ROS)}

Groups of $25 \mathrm{COCs}$ of prepubertal goats were cultured for $24 \mathrm{~h}$ at $38.5^{\circ} \mathrm{C}$ under an atmosphere of $5 \% \mathrm{CO}_{2}$ in air with maximum humidity in $100 \mu \mathrm{L}$ drops of TCM199 (M7528, Sigma) supplemented with $275 \mu \mathrm{g} / \mathrm{mL}$ sodium pyruvate (P-3662, Sigma), $146 \mu \mathrm{g} /$ $\mathrm{mL}$ L-glutamine (G-5763, Sigma), $50 \mu \mathrm{g} / \mathrm{mL}$ gentamycin and roscovitine (R-7772, Sigma) at a concentration of $0,12.5,25,50$ and $100 \mu \mathrm{M}$ as described by Mermillod et al. [6].

A group of 31 COCs of adult goats was cultured at the same conditions than those of prepubertal goats with a roscovitine concentration of $25 \mu \mathrm{M}$.

\subsection{In vitro maturation}

After prematuration, prepubertal goat oocytes were transferred to $100 \mu \mathrm{L}$ drops of maturation medium: TCM199 (M-7528, Sigma) supplemented with $275 \mu \mathrm{g} / \mathrm{mL}$ sodium pyruvate (P-3662, Sigma), $146 \mu \mathrm{g} / \mathrm{mL}$ L-glutamine (G-5763, Sigma), 10\% (v/v) steer serum, $10 \mu \mathrm{g} / \mathrm{mL}$ o-LH (L-5269, Sigma), $10 \mu \mathrm{g} / \mathrm{mL}$ o-FSH (Ovagen ${ }^{\circledR}$, Immuno Chemicals Products Ltd., Auckland, New Zealand), $1 \mu \mathrm{g} / \mathrm{mL} 17 \beta$ estradiol (E-2257, Sigma), $100 \mu \mathrm{M}$ cysteamine (M-9768, Sigma) and $50 \mu \mathrm{g} / \mathrm{mL}$ gentamycin, and incubated under mineral oil (M-3516, Sigma) for $27 \mathrm{~h}$ at $38.5^{\circ} \mathrm{C}$ in a humidified air atmosphere of $5 \% \mathrm{CO}_{2}$. Oocytes not prematured were considered control group.

\subsection{Sperm preparation}

Fresh ejaculates from three fertile males were taken to the laboratory at $38.5{ }^{\circ} \mathrm{C}$. The percentage of motility was assessed under an inverted microscope. Motile spermatozoa were recovered by swim-up [24]. Seventy microliters of semen were placed in each of several conical tubes under $2 \mathrm{~mL}$ defined medium modified by Younis et al. [25] and referred to as $\mathrm{mDM}$ here, and incubated them for $1 \mathrm{~h}$ in a humidified atmosphere of $5 \%$ $\mathrm{CO}_{2}$ in air at $38.5{ }^{\circ} \mathrm{C}$. After incubation, $600 \mu \mathrm{L}$ from the top of each tube was removed and pooled in a sterile $15 \mathrm{~mL}$ centrifuge tube and centrifuged at $200 \times g$ for $10 \mathrm{~min}$. After discarding the supernatant, the resulting sperm pellet was resuspended 1:1 with $\mathrm{mDM}$ medium containing ionomycin (I-0634, Sigma) and heparin (final concentration: $200 \mathrm{nM}$ of ionomycin and $10 \mu \mathrm{g} / \mathrm{mL}$ of heparin) and incubated for $15 \mathrm{~min}$ in a humidified air atmosphere of $5 \% \mathrm{CO}_{2}$ at $38.5{ }^{\circ} \mathrm{C}$ [26].

\subsection{In vitro fertilization}

After maturation, groups of 25 prepubertal goat oocytes were transferred into $100 \mu \mathrm{L}$ fertilization microdrops of modified Tyrode's medium (TALP), as described by Parrish et al. [24], supplemented with $1 \mu \mathrm{g} / \mathrm{mL}$ hypotaurine (H-1384, Sigma) under mineral oil. After capacitation, sperm concentration was assessed with a haemacytometer, and an 
aliquot $(5 \mu \mathrm{L})$ of the sperm suspension was added to the fertilization microdrops (final concentration: $4 \times 10^{6}$ spermatozoa $/ \mathrm{mL}$ ). Gametes were cocultured for $24 \mathrm{~h}$ in a humidified air atmosphere of $5 \% \mathrm{CO}_{2}$ at $38.5^{\circ} \mathrm{C}$.

\subsection{In vitro embryo culture}

At $24 \mathrm{~h}$ post-insemination (hpi), in vitro fertilized oocytes were denuded.

Embryos were cultured in SOF medium ([27], modified by ref. [28]), groups of 18 oocytes were washed twice and placed into $25 \mu \mathrm{L}$ drops of SOF. At $48 \mathrm{hpi}$, was added to the drops $2.5 \mu \mathrm{L}$ of FBS. Embryos were cultured at $38.5^{\circ} \mathrm{C}$ in a humidified atmosphere of $5 \% \mathrm{CO}_{2}, 5 \% \mathrm{O}_{2}$ and $90 \% \mathrm{~N}_{2}$.

\subsection{Assessment of nuclear maturation, fertilization and embryo development}

To evaluate the nuclear stage just after oocyte collection, after prematuration with roscovitine and after $27 \mathrm{~h}$ of in vitro maturation, a sample of oocytes were mechanically denuded, fixed in ethanol (90\%):acetic acid (3:1, v/v) and, after $24 \mathrm{~h}$, stained with $1 \%$ lacmoid (L-7512, Sigma).

To evaluate the pronuclear stage after $17 \mathrm{~h}$ of IVF, a sample of oocytes were processed in the same way as the oocytes fixed after prematuration and IVM. We considered oocytes with a sperm tail in the cytoplasm to be fertilized and classified them in one of the next three groups: 2PN (female pronucleus, male pronucleus and sperm tail; normal fertilization), polyspermy ( 2 or more sperm tails in the cytoplasm with condensed heads or two or more decondensed heads in the cytoplasm) and asynchrony (female pronucleus and a condensed sperm head).

Embryos were assessed with fluorescent microscopy after Hoechst 33342 staining. The percentage of total embryos (number of embryos obtained after 8 days of culture/oocytes), morulae (embryos with 16 or more cells without blastocoele) and blastocysts (embryos with 60 or more cells with blastocoele formation) was evaluated.

\subsection{Gel electrophoresis}

Prepubertal goat oocytes were denuded and separated in three groups of 120 oocytes each one. Group 0 h: oocytes recovered after slicing; Group ROS 25: oocytes cultured for $24 \mathrm{~h}$ with $25 \mu \mathrm{M}$ Roscovitine; Group IVM: oocytes matured for $27 \mathrm{~h}$. A sample of granulosa cells (GC) was used as a positive control of the procedure and also to normalize the results. The cells were lysed by sonication and polypeptides were separated using $10 \%$ SDS polyacrilamide gel electrophoresis as described by Laemmli [29]. Also markers of known weight were used as a control.

\subsection{Immunoblotting}

The electrophoretically separated polypeptides were transferred to a nitrocellulose sheet [30] and blocked by incubation in PBS $0.05 \%$ Tween-20 with 3\% of BSA for $30 \mathrm{~min}$. 
Sheets were incubated with the first antibodies: MAPK (C-14 Santa Cruz Biotechnology, CA), MAPKP (K-23, Santa Cruz Biotechnology) (1/2000), p34 $4^{\text {cdc2 }}$ (sc-54, Santa Cruz Biotechnology) and p34 ${ }^{\mathrm{cdc} 2}$ Tyr-P (sc-7989-R, Santa Cruz Biotechnology) (1/200) for a minimum of $1 \mathrm{~h}$. Then, they were washed in PBS $0.05 \%$ Tween-20 for $15 \mathrm{~min}$ and incubated in the same buffer containing the anti-rabbit (sc-2007, Santa Cruz Biotechnology) or anti-mouse IgG (sc-2008, Santa Cruz Biotechnology) antibody (1/5000 and $1 / 2000$, respectively) for $30 \mathrm{~min}$.

The activity of these proteins was revealed using a blotting chemiolluminiscence detection kit (Supersignal West Dura Extended Duration Substrate of PIERCE) [31].

Experiments were done in triplicate.

\subsection{Statistical analysis}

Differences in results were assessed using Chi-square test $\left(\chi^{2}\right)$ or Fisher test (Graph-Pad Software, San Diego, CA, USA). Differences with a $P<0.05$ were considered statistically significant.

Intensity of the bands on Western blots was measured by a densitometric analysis system: BIO-RAD by the software Quantity One. Differences in results were analyzed by ANOVA test. Differences at $P<0.05$ were considered to be statistically significant.

\subsection{Experimental design}

Experiment 1: The aim of this experiment was to analyze the effect of different ROS concentrations $(0,12.5,25,50$ and $100 \mu \mathrm{M})$ on nuclear arrest of prepubertal goat oocytes. A sample of adult oocytes was used as control to test the effectiveness of the ROS. A sample of prepubertal goat oocytes was analyzed, at time of oocyte collection, in order to test the effectiveness of ROS treatment.

Experiment 2: The aim of this experiment was to analyze embryo development of prepubertal goat oocytes prematured with ROS. According to the results of the experiment 1 , at experiment 2 oocytes were prematured with $0,12.5$ and $25 \mu \mathrm{M}$ of ROS concentrations.

Experiment 3: According to the results of the experiments 1 and 2, the objective of this experiment was to analyze, by western blot, the effect of ROS on MAPK and p34 ${ }^{\mathrm{cdc} 2}$ of prepubertal goat oocytes.

\section{Results}

\subsection{Experiment 1}

Table 1 shows that $64 \%$ of adult goat oocytes exposed for $24 \mathrm{~h}$ to $25 \mu \mathrm{M}$ roscovitine present GV nuclear stage. However, this concentration of roscovitine was notable to block meiosis in prepubertal goat oocytes. After $24 \mathrm{~h}$ of ROS exposition, the percentage of prepubertal goat oocytes at GV stage was 16.9, 28.7, 23.1 and 26.5\% for 12.5, 25, 50 and $100 \mu \mathrm{M}$ ROS concentrations, respectively. 
Table 1

Effect of $24 \mathrm{~h}$ of prematuration with roscovitine in meiosis inhibition of adult and prepubertal goat oocytes (replicates $=7$ )

\begin{tabular}{llllll}
\hline Treatment & Total oocytes & GV $(\%)$ & GVBD $(\%)$ & MI $(\%)$ & MII $(\%)$ \\
\hline Prematuration & & & & & \\
$\quad$ ROS $0 \mu \mathrm{M}$ & 119 & $8(6.7) \mathrm{d}$ & $5(4.2)$ & $50(42.0)$ & $56(47.0) \mathrm{a}$ \\
ROS $12.5 \mu \mathrm{M}$ & 124 & $21(16.9) \mathrm{c}$ & $11(8.9)$ & $53(42.8)$ & $39(31.4) \mathrm{b}$ \\
ROS $25 \mu \mathrm{M}$ & 101 & $29(28.7) \mathrm{b}$ & $10(9.9)$ & $41(40.6)$ & $21(20.8) \mathrm{b}$ \\
ROS $50 \mu \mathrm{M}$ & 104 & $24(23.1) \mathrm{bc}$ & $7(6.7)$ & $42(40.4)$ & $31(29.8) \mathrm{b}$ \\
ROS $100 \mu \mathrm{M}$ & 98 & $26(26.5) \mathrm{bc}$ & $2(2.1)$ & $48(49.0)$ & $22(22.4) \mathrm{b}$ \\
Oocytes of adult goats & 31 & $20(64.5) \mathrm{a}$ & $2(6.4)$ & - & $9(29.1) \mathrm{b}$ \\
with ROS $25 \mu \mathrm{M}$ & & & & & \\
\hline
\end{tabular}

ROS: roscovitine; GV: germinal vesicle; GVBD: germinal vesicle breakdown; MI: metaphase I; MII: metaphase II. Different letters (a-d) within a column are significantly different $\left(\chi^{2}, P<0.05\right)$.

After oocyte collection, 153 oocytes of prepubertal goat oocytes were denuded and stained to assess nuclear stage. Of these oocytes, 11 (7.2\%) were at GV stage, $113(73.8 \%)$ were at GVBD stage, and $19(12.4 \%)$ and $10(6.5 \%)$ were at MI and MII stage, respectively.

\subsection{Experiment 2}

After IVM (Table 2), the percentage of prepubertal goat oocytes at MII was significantly $(P<0.05)$ higher in control group oocytes $(74.4 \%)$ than in oocytes exposed to $0,12.5$ and $25 \mu \mathrm{M}$ ROS for $24 \mathrm{~h}$ and subsequently matured for $27 \mathrm{~h}(54.8,62.5$ and $52.0 \%$, respectively).

Table 3 shows the results of IVF of prepubertal goat oocytes exposed to ROS for $24 \mathrm{~h}$ prior to IVM. The percentage of oocytes sperm-penetrated (total fertilized oocytes) was higher in oocytes prematured without ROS than oocytes at control group (48.5\% versus $27.5 \%)$. No differences were found among ROS groups (12.5 and $25 \mu \mathrm{M})$ and control oocytes in any of the parameters analyzed.

Table 4 shows the results of embryo development after 8 days of in vitro culture. The percentage of total embryos obtained from oocytes exposed to ROS 12.5 and $25 \mu \mathrm{M}$ and from oocytes at control group did not show differences (36.1, 39.4 and 45.2\%,

Table 2

Nuclear stage of in vitro matured prepubertal goat oocytes prematured with roscovitine (replicates $=7$ )

\begin{tabular}{llcccc}
\hline Treatment & Total oocytes & GV $(\%)$ & GVBD $(\%)$ & MI $(\%)$ & MII (\%) \\
\hline Maturation & & & & & \\
$\quad$ Control & 121 & $1(0.8)$ & $2(1.6)$ & $28(23.1)$ & $90 \mathrm{a}(74.4)$ \\
ROS $0 \mu \mathrm{M}$ & 124 & $2(1.6)$ & $2(1.6)$ & $49(39.5)$ & $68 \mathrm{~b}(54.8)$ \\
ROS $12.5 \mu \mathrm{M}$ & 136 & $6(4.6)$ & $6(4.6)$ & $39(28.7)$ & $85 \mathrm{~b}(62.5)$ \\
ROS $25 \mu \mathrm{M}$ & 125 & $12(9.6)$ & $18(14.4)$ & $31(24.8)$ & $65 \mathrm{~b}(52.0)$ \\
\hline
\end{tabular}

ROS: roscovitine; GV: germinal vesicle; GVBD: germinal vesicle breakdown; MI: metaphase I; MII: metaphase II. Different letters (a and b) within a column are significantly different $\left(\chi^{2}, P<0.05\right)$. 
Table 3

In vitro fertilization of oocytes cultured with ROS prior to IVM (replicates $=7$ )

\begin{tabular}{llllcl}
\hline Treatment & $\begin{array}{l}\text { Total inseminated } \\
\text { oocytes }\end{array}$ & Total fertilized (\%) & 2PN (\%) & PS (\%) & ASINC (\%) \\
\hline Control & 69 & $19 \mathrm{~b}(27.5)$ & $17(24.6)$ & $2 \mathrm{~b}(2.9)$ & $0(0)$ \\
ROS $0 \mu \mathrm{M}$ & 66 & $32 \mathrm{a}(48.5)$ & $16(24.2)$ & $13 \mathrm{a}(19.6)$ & $3(4.5)$ \\
ROS $12.5 \mu \mathrm{M}$ & 70 & $17 \mathrm{~b}(24.3)$ & $13(18.6)$ & $4 \mathrm{~b}(5.7)$ & $0(0)$ \\
ROS $25 \mu \mathrm{M}$ & 76 & $27 \mathrm{ab}(35.5)$ & $19(25.0)$ & $3 \mathrm{~b}(3.9)$ & $5(6.6)$ \\
\hline
\end{tabular}

ROS: roscovitine; 2PN: 2 pronuclei; PS: polyspermic; ASINC: asyncronic development of 2PN. Different letters $(a-c)$ within a column are significantly different $\left(\chi^{2}, P<0.05\right)$.

Table 4

Embryo development at day 8 post-insemination of prepubertal goat oocytes prematured with ROS prior to IVM (replicates $=5$ )

\begin{tabular}{llclllc}
\hline & $\begin{array}{l}\text { Inseminated } \\
\text { oocytes }\end{array}$ & Total embryos & 2-7-cell & 8-16-cell & Morulae & Blastocysts \\
\hline Control & 221 & $100(45.2) \mathrm{a}$ & $50(22.6) \mathrm{b}$ & $15(6.8)$ & $3(1.3)$ & $11(5.0) \mathrm{a}$ \\
ROS 0 & 200 & $63(31.5) \mathrm{b}$ & $70(35.0) \mathrm{a}$ & $11(5.5)$ & $2(1.0)$ & 0 \\
ROS 12.5 & 260 & $94(36.1) \mathrm{ab}$ & $86(33.1) \mathrm{a}$ & $17(6.5)$ & $3(1.1)$ & 0 \\
ROS 25 & 231 & $91(39.4) \mathrm{ab}$ & $83(35.9) \mathrm{a}$ & $18(7.8)$ & $6(2.6)$ & $1(0.4) \mathrm{b}$ \\
\hline
\end{tabular}

Different letters ( $\mathrm{a}$ and $\mathrm{b}$ ) within a column are significantly different $\left(\chi^{2}, P<0.05\right)$.

respectively). However, the percentage of blastocysts was higher at control group (5\%) than in prematured groups.

\subsection{Experiment 3}

Determination of MAPK and $\mathrm{p} 34^{\mathrm{cdc} 2}$ in prepubertal goat oocytes.

Figs. 1 and 2 show the results obtained by western blot for the total and active MAPK (phosphorylated form) and for the total and inactive $\mathrm{p} 34^{\mathrm{cdc} 2}$ (Tyrosin phosphorylated form) in granulosa cells, immature oocytes $(0 \mathrm{~h})$, in vitro matured oocytes for $27 \mathrm{~h}$ (IVM) and oocytes exposed to $25 \mu \mathrm{M}$ of roscovitine for $24 \mathrm{~h}$ (ROS 25).

Results of western blots show bands with the same intensity for immature oocytes (Group $0 \mathrm{~h}$ ) and in prematured and IVM-oocytes (groups ROS 25 and IVM, respectively) (Fig. 1, lanes 3-5). MAPK activity was detected in oocytes exposed to ROS and IVMoocytes (groups ROS 25 and IVM) (Fig. 1, lanes 8 and 9) but in immature oocytes the intensity of the band was lighter (Fig. 1, lane 7).

Fig. 2 revealed that the intensity of the bands in total $\mathrm{p} 34^{\mathrm{cdc} 2}$ was similar in immature (Group 0) and cultured oocytes (Groups ROS 25 and IVM) (lanes 4, 2 and 3). A strong band of inactive $\mathrm{p} 34^{\mathrm{cdc} 2}$ (Tyrosin phosphorylated form) was found in immature oocytes (lane 9) and a lighter or mostly inapreciable one in oocytes of groups ROS 25 and IVM (lanes 7 and 8).

The densitometric analysis shows that it does not exist differences neither in total MAPK or total p34 among oocyte groups $(0 \mathrm{~h}: 0.8646 \pm 0.06669$ versus $0.4618 \pm$ 0.05437 ; ROS 25: $0.8788 \pm 0.02006$ versus $0.4876 \pm 0.02057$; IVM: $0.8705 \pm 0.1185$ 

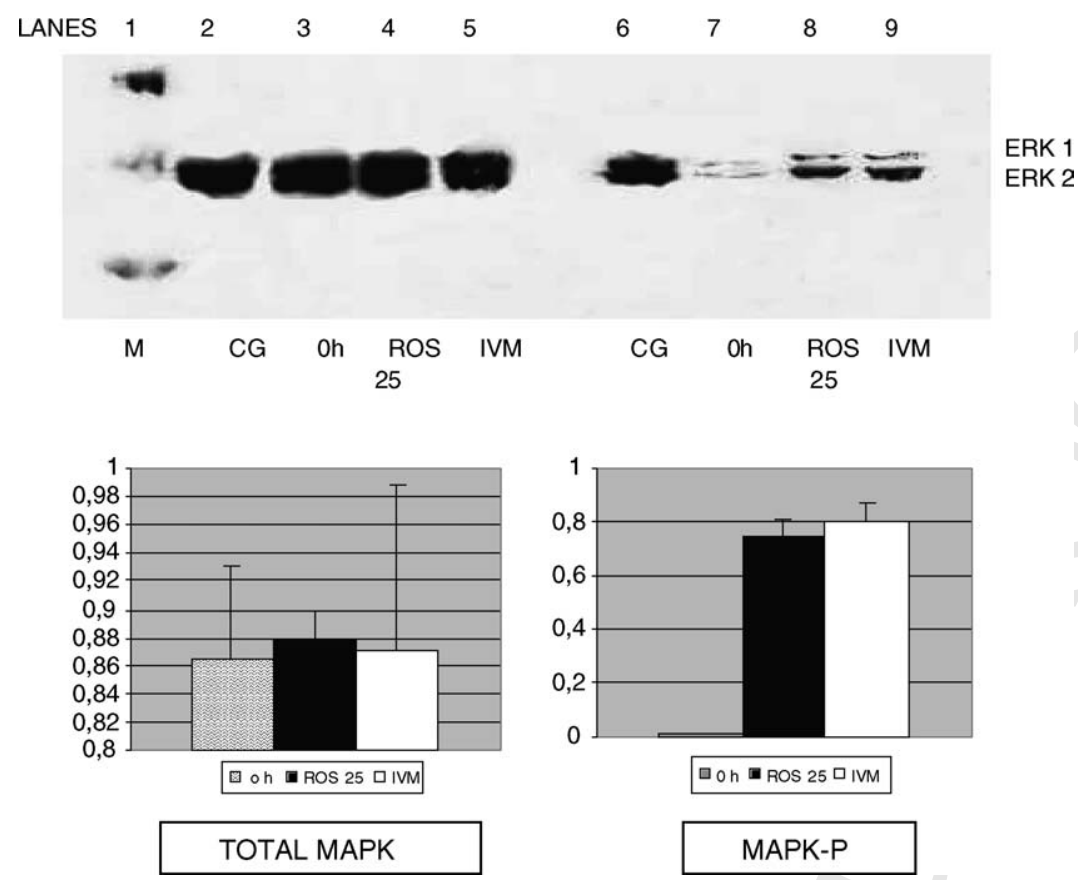

Fig. 1. Western blot for total MAPK (ERK 1 and ERK 2) (lanes 2-5) and active MAPK (lanes 6-9) for granulosa cells (GC), immature oocytes $(0 \mathrm{~h})$, oocytes prematured with roscovitine $25 \mu \mathrm{M}$ (ROS 25$)$ and in vitro maturated oocytes (IVM) of prepubertal goats. Marker (M).

versus $0.5083 \pm 0.0507$, respectively); but we found statistically significant differences among immature oocytes $(0 \mathrm{~h})$ and groups ROS 25 and IVM for the MAPKP $(0.006033 \pm 0.001222$ versus $0.7513 \pm 0.0565$ and $0.8039 \pm 0.06775$, respectively $)$ and the $\mathrm{p} 34^{\text {cdc2 }}$ Tyr-P $(0.6078 \pm 0.04127$ versus $0.01393 \pm 0.01421$ and $0.0750 \pm$ 0.009315 , respectively).

We found that both $\mathrm{p} 34^{\text {cdc2 }}$ and MAPK activity was lower in group $0 \mathrm{~h}$ than in ROS 25 and IVM as it could be expected but roscovitine, at the concentration used in this study, has been unable to block the activity of $\mathrm{p} 34^{\text {cdc2 }}$ and MAPK.

\section{Discussion}

In this study, we demonstrated the effectiveness of roscovitine in arresting adult goat oocytes at nuclear GV stage. The low percentage of prepubertal goat oocytes at GV stage after ROS incubation could be due to the fact that a high percentage of oocytes have already resumed meiosis before ROS exposition. Treatment of prepubertal goat oocytes with roscovitine for $24 \mathrm{~h}$ prior to maturation did not affect normal fertilization (2PN zygotes) or total embryos produced at 8 days post-insemination, while it resulted in a reduced blastocyst formation. Moreover, assessing MAPK and $\mathrm{p} 34^{\mathrm{cdc} 2}$ activity using Western blot 

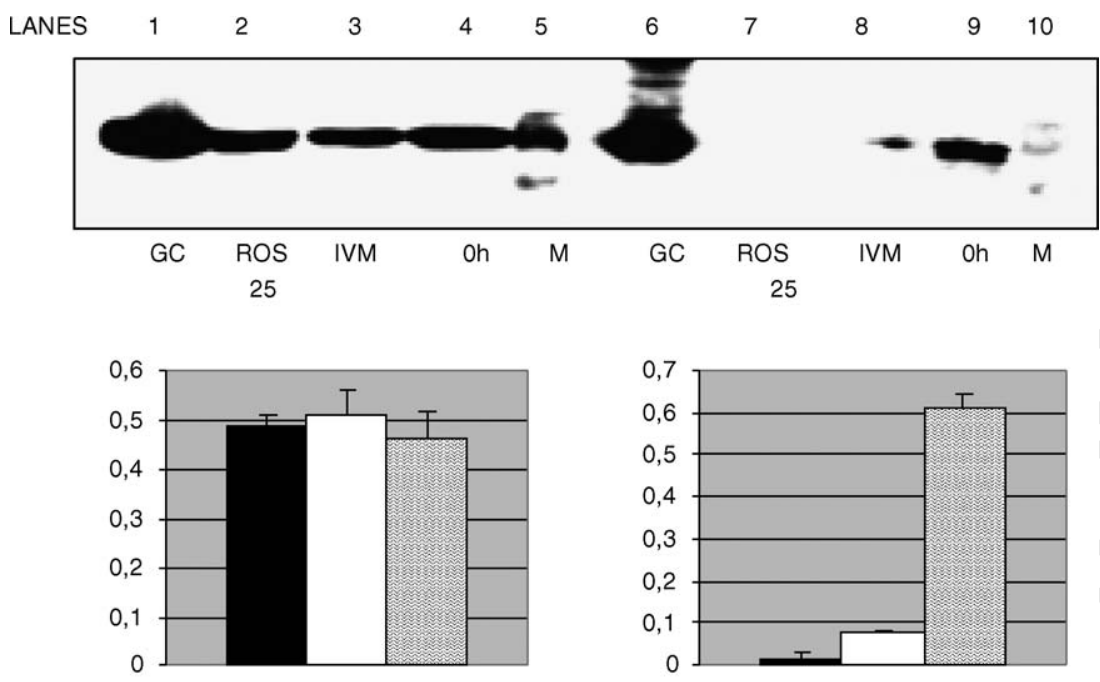

[ ROS 25口IVM 日Oh

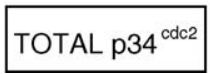

[ ROS 25 पIVM GOh

$$
\mathrm{p} 34^{\mathrm{cdc} 2}-\mathrm{P}
$$

Fig. 2. Western blot for total p34 ${ }^{\mathrm{cdc} 2}$ (lanes 1-4) and p34 ${ }^{\mathrm{cdc} 2}$ tyr-P (lanes 6-9) for granulosa cells (GC), immature oocytes $(0 \mathrm{~h}$ ), oocytes prematured with roscovitine $25 \mu \mathrm{M}$ (ROS 25) and in vitro maturated oocytes (IVM) of prepubertal goats. Marker (M).

we did not find differences between oocytes matured for $27 \mathrm{~h}$ (IVM-oocytes) and oocytes exposed to ROS for $24 \mathrm{~h}$. Differences in MAPK and p34 ${ }^{\text {cdc2 }}$ activity were found between oocytes at collection time $(0 \mathrm{~h})$ and cultured oocytes.

Different concentrations of roscovitine were used to block meiosis activation in pig (50 $\mu \mathrm{M}$ : [32,33]; $80 \mu \mathrm{M}$ : [34]; 25 and $50 \mu \mathrm{M}$ : [22]); cow (25 $\mu \mathrm{M}$ : [6]); calf $(25 \mu \mathrm{M}$ : [35,36]); horse (66 $\mu \mathrm{M}$ : [7]). In our study, we have tested concentrations of 12.5, 25, 50 and $100 \mu \mathrm{M}$. A concentration of $25 \mu \mathrm{M}$ was the optimal dosis to arrest meiosis without detrimental effect on embryo development. However, blastocyt development was reduced in all of the prematured oocytes $(0,12.5$ and $25 \mu \mathrm{M})$ compared to control oocytes $(3.0,1.0$, $1.1 \%$ versus $6.3 \%$, respectively). Furthermore, a degenerative effect was observed in oocytes exposed to 50 and $100 \mu \mathrm{M}$ ROS (data not presented). In these two groups, a high percentage of oocyte degeneration was observed during embryo culture $(N=104$ and $N=98 ; 75.5$ and $72.8 \%$, respectively). Based on these results, the groups of ROS 50 and $100 \mu \mathrm{M}$ were eliminated from the rest of experiments. In our study, roscovitine did not affect in vitro fertilization. The lack of effect of roscovitine on meiosis arrest could be caused because oocytes recovered from ovaries of prepubertal goats slaughtered in a commercial abattoir had reinitiated the meiosis inside follicle or were ready to mature after follicle liberation. The low percentage of oocytes at GV after oocyte collection (7.2\%) compared to oocytes exposed to ROS (29\%) could be explained because the longer time needed to denude and stain the oocytes compared to exposing the oocytes to ROS. Franz 
300

et al. [7] observed lower percentages of GV horse oocytes, after roscovitine exposition for $24 \mathrm{~h}$, in expanded COCs than in compact COCs (57 and 84\%, respectively). These authors suggest that a proportion of oocytes with expanded cumuli at the time of oocyte collection were already maturing or ready to mature if removed from the follicle, and thus roscovitine was less effective in suppressing meiosis.

In the present study, we did not find differences in total, normal (oocytes with 2 pronuclei) or polyspermic fertilization between prematured and control oocytes.

Concentrations of meiotic inhibitors affect meiosis resumption. In cattle oocytes, Mermillod et al. [6], testing different concentrations of roscovitine (12.5, 25, 50 and $100 \mu \mathrm{M}$ ), concluded that doses higher than $25 \mu \mathrm{M}$ increased rates of oocytes blocked at the GV stage compared to $12.5 \mu \mathrm{M}$. These authors concluded that $12.5 \mu \mathrm{M}$ was effective in inhibiting MPF activity, but not effective in inhibiting MAPK activity; thus, allowing oocytes to resume meiosis and progress to MI. Higher doses of roscovitine are also active in inhibiting MAPK activity [20].

Roscovitine inhibits MPF activity, blocking the $\mathrm{p} 34^{\mathrm{cdc} 2}$ subunit of MPF cattle oocytes [6] and also decreases enzyme activity of MAP kinase in pig oocytes [32]. Other authors have found that during prematuration of calf oocytes with roscovitine, several events such as protein synthesis and most of the modifications of protein phosphorilation (Akt/PKB, JNK1/2 and Aurora-A) are not affected by escape to roscovitine prevention [37]. Moreover, there are other two proteins (48 and $64 \mathrm{kDa}$ ), which are specific to matured oocytes which were not blocked in cattle in oocytes prematured with ROS [38]. That suggests that there are alternative pathways in oocyte maturation that this kind of meiotic inhibitor cannot block over. That partial arrest of the events concerning to maturation, could explain the abnormal acceleration of maturation observed after this treatment [38].

In our study, oocytes from prepubertal goats exposed for $24 \mathrm{~h}$ to roscovitine did not arrest meiosis, possibly because meiosis was already re-initiated. Western blot analysis shows that the activity of $\mathrm{p} 34^{\mathrm{cdc} 2}$ and MAPK was detected in oocytes exposed to roscovitine for $24 \mathrm{~h}$ at a similar intensity as in in vitro matured oocytes for $27 \mathrm{~h}$ and higher than the activity of oocytes at collection time. Although oocytes at collection time had reinitiated the meiosis, most of them were at GVBD stage. At this early stage of GVBD, the MPF and MAPK activity starts to rise but they do not reach their highest levels until MI. MPF activity is high at MI and rise at MII. MAPK activity remain high since MI until fertilization. The percentage of oocytes at MI and MII nuclear stage was 40.6 and $20.8 \%$ of ROS incubated oocytes and 23.1 and $74.4 \%$ of IVM-oocytes and 12.4 and $6.5 \%$ of oocytes at collection time. These different results in nuclear maturation would explain the differences in MPF and MAPK activity among oocyte groups.

In goat oocytes, Dedieu et al. [39] have studied the presence of total p34 ${ }^{\mathrm{cdc} 2}$. They detected that total $\mathrm{p} 34^{\mathrm{cdc} 2}$ remained stable during the whole process of maturation from the GV to the MII stage. However, they did not find this protein in meiotically incompetent oocytes.

Prepubertal goat oocytes, independently of the oocyte and sperm treatment used, show a low embryo developmental competence. Salamone et al. [40] observed the kinetics of MPF and MAPK activity during oocyte maturation in calf and cow oocytes, concluding that kinase activity was low at the GV stage $(0 \mathrm{~h})$ and increased several fold at $24 \mathrm{~h}$ after maturation in both oocytes groups. Although the amount of kinase activity 
increased in calf oocytes during maturation, the total activity of MPF and MAPK remained significantly lower than that observed in cow oocytes. These authors concluded that these deficiencies may lead to anomalous ooplasmic maturation and may result in the production of developmentally incompetent oocytes. In our study, we have observed the kinetic activity of MPF and MAPK, but we do not know the degree of these activities, which were possibly as low as those observed in calf oocytes.

According to the results of this experiment, roscovitine was able to block meiosis of adult goat oocytes. Oocytes from prepubertal goats had reinitiated the meiosis before follicular liberation, thus roscovitine was ineffective in blocking meiosis, although these oocytes were fertilized at the same rate as control oocytes. At the time of collection, in spite of oocytes had reinitiated meiosis, they presented inactive $\mathrm{p} 34^{\mathrm{cdc} 2}$ and MAPK, these enzymes were activated during IVM and ROS exposition.

\section{Acknowledgements}

This study was supported by MCyT (Grant AGL2004-0353). The authors thanks to M.J. Palomo for her technical assistance.

\section{References}

[1] Hyttel P, Fair T, Callesen H, Greve T. Oocyte growth, capacitation and final maturation in cattle. Theriogenology 1997;47:23-32.

[2] Gosden R, Krapez J, Briggs D. Growth and development of the mammalian oocyte. BioEssays 1997;19:87582.

[3] Martino A, Mogas T, Palomo MJ, Paramio MT. Meiotic competence of prepubertal goat oocytes. Theriogenology 1994;41:969-80.

[4] Izquierdo D, Villamediana P, Paramio MT. Effect of culture media on embryo development from prepubertal goat IVM-IVF oocytes. Theriogenology 1999;52:847-61.

[5] Armstrong DT. Effects of maternal age on oocyte developmental competence. Theriogenology 2001;55:1303-22.

[6] Mermillod P, Tomanek M, Marchal R, Meijer L. High developmental competence of cattle oocytes maintained at the vesicle stage for $24 \mathrm{~h}$ in culture by specific inhibition of MPF kinase activity. Mol Reprod Dev 2000;55:89-95.

[7] Franz LC, Choi YH, Squires EL, Seidel GE, Hinrichs KE. Effects of roscovitine on maintenance of germinal vesicle in horse oocytes, subsequent nuclear maturation, and cleavage rates after intracytoplasmic sperm injection. Reproduction 2003;125:693-700.

[8] Ponderato N, Lagutina I, Crotti G, Turini P, Galli C, Lazzari G. Bovine oocytes treated prior to in vitro maturation with a combination of butyrolactone $\mathrm{I}$ and roscovitine at low doses maintain a normal developmental capacity. Mol Reprod Dev 2001;60:579-85.

[9] Ponderato N, Crotti G, Turini P, Duchi R, Galli C, Lazzari G. Embryonic and foetal development of bovine oocytes treated with a combination of butyrolactone I and roscovitine in an enriched medium prior to IVM and IVF. Mol Reprod Dev 2002;62:513-8.

[10] Crozet N, Motlik J, Szöllösi D. Nucleolar fine structure and RNA synthesis in porcine oocytes during the early stages of antrum formation. Biol Cell 1981;41:35-42.

[11] Masui Y, Markert C. Cytoplasmic control of nuclear behaviour during meiotic maturation of frog oocytes. J Exp Zool 1971;177:129-46. 
[12] Lohka MJ, Hayes MK, Maller JL. Purification of maturation-promoting factor, an intracellular regulator of early mitotic events. Proc Natl Acad Sci USA 1988;85:3009-13.

[13] Mitra J, Schultz RM. Regulation of the acquisition of meiotic competence in the mouse: changes in the subcellular localization of cdc2, cyclin B, cdc25 and wee1. J Cell Sci 1996;109:2407-15.

[14] Norbury C, Nurse P. Animal cell cycles and their control. Annu Rev Biochem 1992;61:441-70.

[15] Harrou KW, Clarke HJ. Mitogen-activated protein (MAP) kinase during the acquisition of meiotic competence by growing oocytes of the mouse. Mol Reprod Dev 1995;41:29-36.

[16] Pelech SL, Sanghera JS. Mitogen activated protein kinases: versatile transducers for cell signalling. TIBS 1992;17:233-8.

[17] Saeki K, Nagao Y, Kishi M, Nagai M. Developmental capacity of bovine oocytes following inhibition of meiotic resumption by cyclohexamide or 6-dimetilaminopurine. Theriogenology 1997;48:1161-72.

[18] Lonergan P, Khatir H, Carolan C, Mermillod P. Bovine blastocyst production in vitro after inhibition of oocyte meiotic resumption for $24 \mathrm{~h}$. J Reprod Fertil 1997;109:355-65.

[19] Kastrop PMM, Bevers MM, Destrée OHJ, Kruip TAM. Analysis of protein synthesis in morphologically classified bovine follicular oocytes before and after maturation in vitro. Mol Reprod Dev 1990;26: 222-6.

[20] Meijer L, Kim SH. Chemical inhibitors of cyclin-dependent kinases. Methods Enzymol 1997;283: 113-28.

[21] Motlik J, Pavlock A, Kubelka M, Kalous J, Kalab P. Interplay between cdc2 kinase and MAP kinase pathway during maturation of mammalian oocytes. Theriogenology 1998;49:461-9.

[22] Schoevers EJ, Bevers MM, Roelen BA, Colenbrander B. Nuclear and cytoplasmic maturation of sow oocytes are not synchronized by specific meiotic inhibition with roscovitine during in vitro maturation. Theriogenology 2005;63:1111-30.

[23] Ma S, Lan G, Miao Y, Wang Z, Chang Z. Hypoxanthine (HX) inhibition of in vitro meiotic resumption in goat oocytes. Mol Reprod Dev 2003;66:306-13.

[24] Parrish JJ, Susko-Parrish JL, Leibfried-Rutledge ML, Crister ES, Eyeston WH, First NL. Bovine in vitro fertilization with frozen thawed semen. Theriogenology 1986;25:591-600.

[25] Younis AL, Zuelke KA, Harper KM, Oliveira MAL, Brackett BG. In vitro fertilization of goat oocytes. Biol Reprod 1991;44:1177-82.

[26] Wang B, Baldassarre H, Tao T, Gauthier M, Neveu N, Zhou JF, et al. Transgenic goats by DNA pronuclear micro injection of in vitro derived zygotes. Mol Reprod Dev 2002;63:437-43.

[27] Tervit HR, Whittingham DG, Rowson LEA. Successful culture of in vitro sheep and cattle ova. J Reprod Fertil 1972;30:493-7.

[28] Takahashi Y, First NL. In vitro development of bovine one-cell embryos: influence of glucose, lactate, pyruvate, amino acids and vitamins. Theriogenology 1992;37:963-78.

[29] Laemmli UK. Cleavage of structural proteins during assembly of the head of bacteriophage T4. Nature 1979;227:680-5.

[30] Burnet WN. Western blotting: electrophoretic transfer of proteins from sodium dodecyl sulphate-polyacrylamide gels to ummodified nitrocellulose and radiographic detection with antibody and radioiodinated proteins. J Anal Biochem 1981;112:195-203.

[31] Mattson DL, Bellehumeur TG. Comparison of the three chemiluminiscent horseradish peroxidase substrates for immumoblotting. Anal Biochem 1996;240:306-8.

[32] Krischek C, Meinecke B. Roscovitine, a specific inhibitor of cyclin-dependent protein kinases, reversibly inhibits chromatin condensation during in vitro maturation of porcine oocytes. Zygote 2001;9:309-16.

[33] Le Beux G, Richard J, Sirard MA. Effect of cycloheximidine, 6-DMAP, roscovitine and butyrolactone I on resumption of meiosis in porcine oocytes. Theriogenology 2003;60:1049-58.

[34] Ju JC, Tsay C, Ruan CW. Alterations and reversibility in the chromatin, cytoskeleton and development of pig oocytes treated with roscovitine. Mol Reprod Dev 2003;64:482-91.

[35] Donnay I, Faerge I, Grondahl C, Verhaeghe B, Sayoud H, Ponderato N, et al. Effect of prematuration, meiosis, activating sterol and enriched medium on the nuclear maturation and competence to development of claf oocytes. Theriogenology 2004;62:1093-107.

[36] Albarracin JL, Morato R, Izquierdo D, Mogas T. Effects of roscovitine on the nuclear and cytosqueletal components of calf oocytes and their subsequent development. Theriogenology, in press. 
[37] Vigneron C, Perreau C, Dalbies-Tran R, Joly C, Humblot P, Uzbekova S, et al. Protein synthesis and mRNA storage in cattle oocytes maintained under meiotic block by roscovitine inhibition of MPF activity. Mol Reprod Dev 2004;69:457-65.

[38] Vigneron C, Perreau C, Dupont J, Uzbekova S, Prigent C, Mermillod P. Several signalling pathways are involved in the control of cattle oocyte maturation. Mol Reprod Dev 2004;69:466-74.

[39] Dedieu T, Gall L, Hue E, Ledan E, Crozet N, Ruffini S, et al. p34 cdc2 expression and meiotic competence in growing goat oocytes. Mol Reprod Dev 1998;50:251-62.

[40] Salamone DF, Damiani P, Fissore RA, Robl JM, Duby RT. Biochemical and Developmental evidence that ooplasmic maturation of prepubertal bovine oocytes is compromised. Biol Reprod 2001;64:761-8. 